\title{
METODOLOGIA PARTICIPATIVA NA ABORDAGEM DE QUESTÕES SOCIOCIENTÍFICAS: CONSIDERAÇÕES ACERCA DO DIÁLOGO
}

\section{PARTICIPATORY METHODOLOGIES IN THE APPROACH SOCIOSCIENTIF ISSUES: CONSIDERATION ABOU THE DIALOGUE}

\author{
Katia Dias Ferreira Ribeiro ${ }^{1}$ \\ ORCID iD: 0000-0001-9571-0192
}

\begin{abstract}
RESUMO
As características das questões sociocientíficas (QSC) exigem que a metodologia de ensino e aprendizagem empregada para seu desenvolvimento permita expressar e tornar concretos seus objetivos educacionais, bem como favorecer o protagonismo dos sujeitos participantes do processo educacional; assim sendo, há uma aproximação às metodologias de ensino e aprendizagem participativas, problematizadoras e colaborativas, aqui chamadas de metodologias participativas (MP). A partir dos pressupostos teóricos de QSC e MP, percebe-se que o elemento que os aproxima é o diálogo. Assim posto, na intenção de contribuir com essa discussão e na certeza de que ainda são um desafio a análise e a propositura de modelos metodológicos e técnicas adequadas para o desenvolvimento de análise de QSC nas ações educacionais, tem-se como objetivo apresentar uma metodologia matricial, tida como uma MP, a qual foi elaborada e utilizada na abordagem de QSC em um processo de formação docente, destacando o diálogo como elemento de aproximação entre QSC e MP. Para isso, elucidam-se três objetivos educacionais favorecidos pelo diálogo: a transposição da consciência ingênua para a consciência crítica, a concretização da interdisciplinaridade e a promoção da aprendizagem de conhecimentos científicos.
\end{abstract}

Palavras-chave: Questões sociocientíficas. Metodologia participativa. Metodologia matricial. Diálogo.

\begin{abstract}
The characteristics of socioscientific issues (SSI) require that the teaching and learning methodology used for their development allows then to express and make concrete their educational objectives, as well as favor the protagonism of the subjects participating in the educational process; therefore, there is an approach to methodologies of teaching and learning participatory, problematizing and collaborative, here called participatory methodologies (PM). From the theoretical assumptions of SSI and PM it is clear that the element that brings then together is dialogue. Thus, in order to contribute to this discussion and the certainty that they are still a challenge to analyze and propose $r$ methodological models and techniques used for the development of SSI analysis in educational actions, aims to present a matrix methodology, taken as a PM , which was elaborated and used in the SSI approach in a teacher training process, highlighting dialogue as an element of approximation between SSI and PM. To this end, three educational objectives favored by dialogue are elucidated: a transposition from naive awareness to critical awareness, a concretization of interdisciplinarity and a promotion of the learning of scientific knowledge.
\end{abstract}

Keywords : Socioscientif issues. Participatory methodologies. Matrix metodology. Dialogue.

\footnotetext{
${ }^{1}$ Doutora em Educação em Ciências e Matemática pela Rede Amazônica de Educação em Ciências e Matemática (REAMEC/UFMT). Docente do Programa de Pós-Graduação em Ensino de Ciências e Matemática (PPGECM) da Universidade Federal de Mato Grosso (UFMT) e do Instituto Federal de Educação, Ciência e Tecnologia (IFMA), Porto Franco, Maranhão, Brasil. Endereço para correspondência: Rua Joaquim Pereira, número 197, Centro, Porto Franco, MA, Brasil, CEP 65970-000. E-mail: katiadfr2@ hotmail.com.
} 


\section{INTRODUÇÃO}

As questões sociocientíficas (QSC) têm sido utilizadas de forma significativa e profícua nos processos educacionais. Reconhece-se a potencialidade da utilização de análise de questões sociocientíficas e, devido às suas características, é exigido que a metodologia de ensino e aprendizagem utilizada para sua análise possa permitir expressar e tornar concretos seus objetivos educacionais e o protagonismo dos sujeitos participantes do processo educacional. Assim sendo, há uma aproximação às metodologias de ensino e aprendizagem participativas, problematizadoras e colaborativas, ou somente, metodologias participativas (MP).

É imprescindível, no trabalho com QSC em sala de aula, o alinhamento com metodologias de ensino e aprendizagem como as metodologias participativas, que têm como fundamento "a interlocução entre professor e aluno, a problematização da realidade, a prática social que se tem e que se quer ter, os vínculos entre educação e sociedade, entre educação e política, dentre outros aspectos" (ARAÚJO, 2017, p. 18); bem como a interlocução entre os pares. Ainda segundo o autor, a metodologia participativa está aliançada ao partilhamento do conhecimento, à participação por parte dos sujeitos, e pode se referir ao diálogo, já que envolve os alunos em debates, discussões. Assim considerado, destaca-se o diálogo como fator intercessor entre QSC e MP.

Essa aproximação foi feita de forma profícua por Ribeiro (2016), quando foi utilizada uma metodologia matricial (MEDINA; SANTOS, 1999) como parte das atividades realizadas por professores de Ciências Naturais e Matemática em formação inicial ao participarem de uma ação educativa para analisar uma QSC. Diante do que foi realizado e conforme as perspectivas vislumbradas com o trabalho com a metodologia matricial na análise de QSC na formação docente, questiona-se a potencialidade dessa junção - metodologia matricial e QSC - na promoção de diálogos de forma a favorecer a constituição da consciência crítica, da interdisciplinaridade e da aprendizagem de conhecimentos científicos, o que se configura como o problema científico que deu origem a este trabalho.

Assim posto, na intenção de contribuir com essa discussão e na certeza de que ainda são um desafio a análise e a propositura de modelos didáticos para o desenvolvimento de análise de QSC na formação docente, neste texto, tem-se como intento elucidar três objetivos educacionais de QSC favorecidos pelo diálogo: a transposição da consciência ingênua para a consciência crítica, a concretização da interdisciplinaridade e a promoção da aprendizagem de conhecimentos científicos. Para tanto, aqui se utiliza de um recorte da intervenção pedagógica 
apresentada por Ribeiro (2016) em que se destacam a elaboração e a condução das MP, as quais merecem reflexões e refinamentos de forma a serem mais bem utilizadas na formação docente.

Este texto faz parte de um estudo realizado com o propósito de refletir sobre o sucesso das estratégias e dos recursos didáticos, bem como sobre o aprendizado dos sujeitos envolvidos no processo educativo, e caminha no sentido de estabelecer contribuições empíricas para o trabalho de QSC na formação docente, mais especificamente no ensino e aprendizagem de conhecimentos para a docência, apontando necessárias adequações e modificações. A contribuição básica da avaliação da ação formativa é a melhoria de sua qualidade, levando-se em consideração a coerência interna, a coerência com as bases teóricas e a percepção dos sujeitos.

Dessa forma, caracteriza-se esta pesquisa como qualitativa com interesse na compreensão de modelos metodológicos e na interpretação de informações de forma a construir um corpo de conhecimento que possa contribuir para melhoria dos processos formativos. $\mathrm{O}$ objeto de análise são as matrizes e a proposta de seu preenchimento a fim de trazer elementos que possam elucidar o estabelecimento do diálogo, que é um dos objetivos pretendidos com a utilização das MP na análise de QSC.

A fim de cumprir o que aqui se propõe, apresenta-se uma abordagem sobre QSC e sua utilização em processos formativos, sejam eles em qualquer nível de formação; logo depois, um entendimento sobre MP e o alinhamento de seus pressupostos com os da utilização de QSC, bem como se apresenta uma explicação da metodologia matricial. Em sequência, descreve-se a construção e utilização da metodologia matricial; e, por fim, fazem-se reflexões sobre o seu uso, tendo como orientação um aspecto importante tanto no processo de análise de QSC quanto no uso de MP: o diálogo.

\section{QUESTÕES SOCIOCIENTÍFICAS NOS PROCESSOS FORMATIVOS}

Entende-se por questões sociocientíficas (QSC) controvérsias sobre temas sociais que estão relacionados a conhecimentos científicos com os quais as pessoas podem se confrontar em seu dia a dia. Para Ratcliffe e Grace (2003), as questões sociocientíficas têm uma base na ciência, frequentemente nas fronteiras do conhecimento científico, apresentam controvérsias, envolvem formação de opiniões, fazem escolhas em nível pessoal ou social, são frequentemente divulgadas pela mídia, lidam com informações que não são conclusivas por si sós, abordam dimensões locais, nacionais e globais correlatas a estruturas políticas e sociais, envolvem uma análise custo-benefício em que o risco interage com valores, podem envolver a consideração 
do desenvolvimento sustentável, envolvem valores e raciocínio ético e podem exigir uma certa compreensão de probabilidade e risco.

Santos, Silva e Silva (2018) (re)definem a conceituação de QSC admitindo três elementos: possuem relação com a ciência ou tecnologia, constituem-se em um dilema social e apresentam uma controvérsia de ordem moral. Assim sendo, o estudo de QSC possibilita o desenvolvimento da capacidade de tomada de decisão, entendida como o propósito mais amplo da formação para a cidadania.

Para Nunes-Neto e Conrado (2018),

\begin{abstract}
Questões sociocientíficas (QSC) são problemas ou situações controversas e complexas que podem ser transpostos para a educação científica, por permitirem uma abordagem contextualizada de conteúdos interdisciplinares ou multidisciplinares, sendo os conhecimentos científicos fundamentais para a compreensão e a busca de soluções para estes problemas. Todavia, além dos conhecimentos científicos, particularmente, conhecimentos de história e de filosofia (sobretudo de ética) são relevantes e geralmente mobilizados na abordagem desses problemas. Além dos conhecimentos científicos, o uso das QSC, no ensino, contribui para mobilizar valores, habilidades e atitudes. Aspectos culturais, econômicos e políticos são também comuns na discussão de QSC, sendo particularmente interessantes para contextualizar a ciência e a tecnologia, ensinadas em tal perspectiva. (NUNES-NETO; CONRADO, 2018, p. 15).
\end{abstract}

A análise de QSC possibilita o desenvolvimento da tomada de decisões, colaborando na formação para a cidadania e, nesse sentido, é preciso oportunizar aos sujeitos da educação a capacidade de analisar a controvérsia sob diferentes pontos de vista (SANTOS; SILVA; SILVA, 2018). É defendido por Reis (2013) que a abordagem de QSC é útil tanto em relação à aprendizagem da ciência quanto em relação ao desenvolvimento cognitivo, social, político, moral e ético dos sujeitos envolvidos.

Conrado (2013) expõe que são vários os objetivos educacionais relacionados à abordagem de QSC nos processos de ensino e aprendizagem, incluindo "a aprendizagem de conteúdos disciplinares, o desenvolvimento de habilidades argumentativas, a compreensão de aspectos epistemológicos da ciência, o desenvolvimento de atitudes positivas em relação à ciência; o aumento de sensibilidade moral" (CONRADO, 2013, p. 24). Santos, Silva e Silva (2018) afirmam que as pesquisas no contexto brasileiro têm se firmado no campo da argumentação/desenvolvimento de habilidades argumentativas.

As temáticas utilizadas nas discussões emergem de formas diferentes, podendo ser aquelas que têm evidência na mídia envolvendo uma discussão atual, ou que tenham vínculo com a realidade local ou com o interesse dos alunos, ou ainda que tenham relação com o conteúdo abordado ou questão que seja considerada relevante para o professor abordar em sala 
de aula, tais como pesquisas com células-tronco, e-lixo, legalização da maconha e lei de biossegurança (SOUSA; GHELEN, 2017). Em seu estudo, Santos, Silva e Silva (2018) listam temas encontrados nos trabalhos pesquisados e entre eles estão, por exemplo, meio ambiente e uso de novas biotecnologias, construção de uma hidrelétrica, ligações elétricas irregulares, criacionismo x evolucionismo.

As questões a serem tratadas podem ser de abrangência local, regional, nacional ou global. O tratamento de problemas e questões sociais locais vinculados ao entorno dos sujeitos, que tenham significado real para eles, e a busca de soluções para esses problemas, como feito em Ribeiro (2016), tornam a discussão mais próxima e podem gerar um compromisso social efetivo, pois quanto mais se vai conhecendo uma realidade tanto mais é impossível tornar-se neutro diante dela. Para Costa (2016), esse tipo de tratamento de questões fortalece o entendimento sobre a relevância da educação em ciências. Nesse sentido, esse autor defende, além de outros fatores, construções centradas nas comunidades em que vivem os sujeitos, focando em recursos e questões locais.

As QSC são utilizadas em diversos níveis de escolaridade, incluindo a formação docente (cf. CARVALHO; CARVALHO, 2012; MARTÍNEZ PÉREZ, 2010, 2012; RIBEIRO, 2016). Saucedo e Pietrocola (2019) exploraram 120 publicações originadas da consulta às Atas do Encontro Nacional de Pesquisa em Educação em Ciências (ENPEC) e à biblioteca virtual Education Resources Information Center (ERIC). Das atas do ENPEC, foram analisadas 46 produções, sendo que 8 delas $(17,4 \%)$ são referentes à formação docente. Das 74 produções resultantes da busca na base ERIC, $10(13,5 \%)$ têm a formação docente como um contexto de estudo. Acreditamos ser um número que precisa ser ampliado.

Trabalhos que envolvem QSC na formação docente vêm sendo desenvolvidos e apontam possibilidades e potencialidades das discussões para uma adequada formação profissional. Em seu trabalho, Carvalho e Dantas (2019) analisaram a produção científica sobre a utilização de QSC na formação docente e, em todas as 35 produções analisadas pelas autoras, são ressaltadas as contribuições da abordagem de QSC, entre as quais destacam-se: aprendizagem de competências do pensamento crítico, desenvolvimento de competências profissionais, compreensão da natureza da ciência e suas múltiplas relações com a tecnologia e a sociedade. As autoras ainda constatam que são as poucas pesquisas, em torno de $33 \%$, que foram realizadas apenas na formação inicial de professores.

Ribeiro e Darsie (2014, 2016a, 2016b, 2017, 2018) revelam um caminhar no sentido da compreensão da aprendizagem de conhecimentos para a docência por professores em formação inicial com a utilização de análise de QSC. Como sistematização e ampliação desses estudos, 
Ribeiro (2016) propõe, analisa e defende o uso de abordagem de QSC na formação docente na intenção de formar profissionais que assumam uma postura interdisciplinar e crítica no processo educativo, bem como um compromisso político e social em sala de aula, na escola ou em outras instituições ou espaços.

Apesar dos obstáculos e dos desafios, pode-se sintetizar do trabalho de Ribeiro (2016) que a inserção de discussões sobre uma QSC da realidade vivencial dos sujeitos envolvidos nos processos formativos traz contribuições importantes para a aprendizagem de conhecimentos para a docência. Aliado a isso, desperta-se para a necessidade de estruturar conhecimento metodológico a fim de planejar ações educativas que coadunem com as perspectivas do uso de QSC na formação docente, o que leva ao encontro com as MP.

\section{OS PRESSUPOSTOS DAS METODOLOGIAS PARTICIPATIVAS}

No trabalho com QSC, entende-se como importante o uso de metodologias em que haja participação efetiva do aluno como sujeito de seu aprendizado e, mais que isso, que favoreça diálogos diversos. Nessa perspectiva, vislumbra-se a utilização de metodologias participativas (MP).

Etimologicamente, metodologia significa "caminho que devemos seguir para chegar a um fim"; e se tratando de metodologia participativa, diz respeito aos passos educativos que devemos seguir para alcançar um objetivo educacional (NOGUERA, 2005).

Devemos fazer referência ao termo participação "quando não nos limitamos a ser espectadores do que se passa ao nosso redor, senão que intervimos, nos implicamos e tomamos parte de forma continuada em algo" (NOGUERA, 2005, p. 93, tradução nossa).

Ressalta-se, contudo, que o trabalho tanto com QSC quanto com MP exige uma mudança de pensamento. A mudança de ação sem uma mudança de pensamento não se sustenta. Falar de QSC e MP é, antes de mais nada, estar inserido em um processo de reflexão sobre como nos situamos teoricamente com relação à sociedade, à função social da escola/universidade, ao processo de ensinar e aprender, e ao papel do professor e do sujeito da aprendizagem no processo educacional; sobre os conteúdos da aprendizagem, do que é conhecimento e o projeto de sociedade que defendemos; e ainda sobre as necessidades formativas dos professores no contexto brasileiro no século XXI.

Nesse mesmo raciocínio, Araújo (2017, p. 20) apresenta que "uma metodologia de ensino guarda em si uma orientação filosófica fundada em concepções de homem, de mundo, de sociedade, de história, de existência, de educação entre outros aspectos" que, mesmo que 
não sejam expressas, orientam a ação educativa e o processo pedagógico. Duas dimensões então são tidas como imprescindíveis pelo autor no comprometimento com MP: dimensão de ordem conceitual e dimensão de ordem operacional. É preciso o entendimento dos pressupostos teóricos da proposta e, a partir daí se empenhar em uma necessária renovação de pensamento que conduzirá a uma disposição de mudanças de ações.

Costa (2016, p. 88-89) explicita que "são necessárias mudanças metodológicas e pedagógicas que promovam estratégias diferenciadas e um ensino centrado no aluno, em que o papel do professor é cada vez mais o de orientar e cada vez menos o de transmissor de conteúdos". Quando se fala em um ensino centrado no aluno, protagonizado pelo aluno, percebe-se no quadro educacional atual, de forma geral, uma familiaridade com o termo metodologia ativa (MA) e talvez não seja tão familiar o termo metodologia participativa (MP), ou talvez haja o uso indistinto dos dois termos. Porém não é só uma questão de vocábulo, pois ambas representam um avanço em relação ao processo educacional centrado no professor. Para Veiga e Fernandes (2017), há um movimento evolutivo a ser considerado no campo tanto epistemológico quando metodológico, quando se fala de MA e MP.

A metodologia ativa se configura entre o final do século XIX e início do século XX no âmbito do movimento da Escola Nova, o qual foi inaugurado na Inglaterra e materializou-se no Brasil nos anos 30 do século passado. Saviani (2013) apresenta que a Escola Nova ganha terreno no Brasil após a promulgação da Constituição de 1934 e sua predominância na educação brasileira vai até cerca de 1960 .

Nessa tendência, que faz parte da Pedagogia Liberal, a educação é um processo interno, parte das necessidades e dos interesses individuais necessários para a adaptação ao meio, em que se valoriza a autoeducação, o ensino centrado no aluno e no grupo (LUCKESI, 2011). Categorias tais como necessidade, desejo, interesse, esforço, atividade, experiência, adaptação, meio ambiente, aprendizagem, entre outros são tidos como instrumentos conceituais básicos nos fundamentos da metodologia ativa (ARAÚJO, 2017).

Na década de 60 do século passado, a Escola Nova começa a apresentar sinais de crise e, nesse contexto, delineia-se a pedagogia tecnicista, a qual se impõe a partir de 1969. Na década de 1970, o regime militar tenta implantar uma orientação pedagógica centrada nas ideias de racionalidade, eficiência e produtividade, características consideradas básicas da pedagogia tecnicista (SAVIANI, 2013). Na tendência liberal tecnicista, compete à educação escolar "organizar o processo de aquisição de habilidades, atitudes e conhecimentos específicos, úteis e necessários para que os indivíduos se integrem na máquina do sistema social global" (LUCKESI, 2011, p. 80), tendo como objetivo imediato a preparação de indivíduos para o 
mercado de trabalho, sendo o aluno um indivíduo responsivo e espectador diante da verdade objetiva, como o professor também o é.

Ainda da década de 70 do século XX, desencadeia-se uma crítica à pedagogia tecnicista. Educadores fazem críticas ao regime militar e à sua proposta educacional, apoiados na concepção crítico-reprodutivista de educação, a qual posteriormente foi submetida à crítica por conta de seu caráter não dialético. Apesar de seu caráter crítico, por levar em consideração os determinantes sociais da educação, essa concepção desconsidera que a educação interfere na sociedade (SAVIANI, 2013).

Esse quadro de contestação à concepção crítico-reprodutivista e de análise mais profunda da questão educacional, pesando o necessário reconhecimento de que a educação interfere na sociedade, podendo contribuir para sua transformação, configura-se uma passagem da visão crítico-mecanicista para uma visão crítico-dialética, histórico-crítica (SAVIANI, 2013). A pedagogia histórico-crítica faz parte da pedagogia progressista, sendo que esta se caracteriza pelo fato de, "partindo de uma análise crítica das realidades sociais, sustentam implicitamente as finalidades sociopolíticas da educação" (LUCKESI, 2011, p. 83). O aluno aqui é considerado um ser social e, com isso, a escola tem a função de preparar esse aluno para participar ativamente na sociedade.

Estes são, em síntese, os movimentos evolutivos colocados por Veiga e Fernandes (2017) que configuram a passagem da MA para a MP. Os autores acrescentam que:

\begin{abstract}
As metodologias ativas nesse processo evolutivo passam a ser denominadas de metodologias participativas, problematizadoras e colaborativas construídas em outro contexto histórico, político-social e temporal. Esse processo é complexo por apresentar outras configurações epistemológicas mais condizentes com as características sociopolíticas, educacionais e culturais da sociedade brasileira contemporânea. As metodologias participativas, problematizadoras e colaborativas envolvem procedimentos e técnicas diversificadas para promover as relações interpessoais dialógicas e a participação dos estudantes de forma colaborativa. (VEIGA; FERNANDES, 2017, p. 76).
\end{abstract}

Entre o final dos anos 1950 e a primeira metade dos anos 1980, a participação ganhou centralidade nas discussões sobre as pedagogias no Brasil (ARAÚJO, 2017). Atentando-se ao contexto temporal, percebe-se, como colocado pelo autor, que o novo, no caso a MP, vinha se manifestando no interior do velho, que é a MA, desde o final dos anos 50.

O que se identifica nesse movimento são aspirações por uma sociedade fundada, entre outros, na libertação, no diálogo, na superação do capitalismo, na pedagogia a ser constituída pelos trabalhadores, na democratização da escola e de sua gestão, na democratização política (ARAÚJO, 2017). 
Por fim, podemos afirmar que:

A metodologia participativa se fundamenta nos processos de troca (de conhecimentos, experiências, vivências, sentimentos, etc), de resolução colaborativa de problemas e de construção coletiva de conhecimentos que são propiciados entre os sujeitos que compõem um grupo. (NOGUERA, 2005, p. 93, tradução da autora).

Mesmo sendo outra definição para a MP, ela deve sinalizar que se trata de:

\begin{abstract}
Um conjunto de processos, procedimentos, técnicas e ferramentas que envolvem ativamente o aluno no processo de ensino/aprendizagem, quer dizer, se trata de um enfoque metodológico de caráter interativo, baseado na comunicação dialógica professor/aluno e aluno/aluno, que aumenta o envolvimento responsável do estudante e que implica a satisfação e o enriquecimento, tanto do docente como do aluno (NOGUERA, 2005, p. 93-94, tradução da autora).
\end{abstract}

Apesar de todos os benefícios favorecidos pelo uso de MP, não se deve desconsiderar que um método deve estar a serviço dos objetivos educacionais, que uma mesma metodologia não serve para toda e qualquer circunstância e que o professor deve mobilizar os conhecimentos para a docência a fim de planejar as ações mais adequadas para cada situação educacional. Além disso, também é importante não desconsiderar que, em trabalhos cooperativos, podem surgir conflitos sociocognitivos que precisem ser conduzidos e tratados adequadamente para que possam favorecer o processo de ensino e aprendizado.

\title{
4 A ELABORAÇÃO E CONDUÇÃO DE PREENCHIMENTO DAS MATRIZES
}

A MP envolve quatro termos-chave: participação, compartilhamento, colaboração e cooperação. Todos esses termos têm significados próximos, apesar de algumas raízes etimológicas diferentes. Esses termos dizem respeito ao fazer coisas juntos, partilhar, ser companheiro, ser parceiro, trabalhar de comum acordo, contribuir com a realização de algo, auxiliar (ARAÚJO, 2017). No campo pedagógico, esses termos se expressam em técnicas que privilegiam o diálogo, a troca de ideias, a atuação em conjunto para um mesmo fim, as relações interpessoais dialógicas, a participação colaborativa, e é com esse entendimento que se vai ao encontro da metodologia matricial proposta por Medina e Santos (1999), o método Proposta de Participação-Ação para a Construção do Conhecimento (PROPACC).

O PROPACC é entendido por Medina e Santos (1999) como um método de capacitação em educação ambiental, fundamentado em uma reelaboração teórica e prática à luz de três perspectivas teóricas tidas como emergentes na época: do construtivismo, como processo 
individual e social de construção de conhecimento e dos processos de aprendizagem; da concepção de uma perspectiva da realidade do conhecimento e dos processos de ensinoaprendizagem; da teoria crítica superadora da visão técnica e instrumental. No campo metodológico, os autores apoiaram-se nos aportes da investigação-ação e no método de elaboração participativa de projetos Ziel-Orientierte Projekt Planung (ZOOP), em português, Planejamento de Projetos Orientada por Objetivos.

A metodologia proposta para ser utilizada na formação de multiplicadores da educação ambiental consiste em um processo de elaboração e reelaboração coletiva de doze matrizes, divididas em grupos de seis em dois módulos. Nessa proposta é que se fazem adaptações para que seja utilizada na análise de QSC, construindo-se quatro matrizes.

Ribeiro (2016), tendo como foco a aprendizagem de conhecimentos para a docência, apresenta que, na construção das matrizes, foi favorecida a utilização de conhecimentos científicos para a compreensão do objeto de estudo, com possibilidades de estabelecimento de relações interdisciplinares e identificação dos instrumentos conceituais importantes para responder aos problemas propostos. Os professores em formação foram levados a mobilizar e reconhecer as limitações dos conhecimentos disciplinares.

Ribeiro, Trevisan e Trevisan (2017) se empenharam na busca da compreensão da potencialidade pedagógica que a construção coletiva de matrizes desenvolvida por Ribeiro (2016) tem na aprendizagem de conhecimento para a docência. Enuncia-se que o trabalho possibilitou a mobilização e a construção de conhecimentos e também que os participantes tomaram consciência da complexidade do fenômeno estudado e tiveram oportunidade de desenvolver o pensamento crítico; assim houve a promoção de engajamento e comprometimento com o grupo.

As matrizes são descritas a seguir, bem como a forma como foi conduzida a ação pedagógica com os professores em formação inicial.

A Matriz 1 (Quadro 01) se configura como a análise e o diagnóstico de problemas socioambientais, considerando os níveis global, nacional, regional e local. A matriz ajuda a refletir sobre a problemática socioambiental, próxima e distante, devendo estabelecer relações entre elas:

Sob a orientação, segundo Medina e Santos (1999), define-se que a formulação do problema se dá atentando para as seguintes observações: formular os problemas socioambientais como uma condição negativa que se deseja superar; incorporar que um problema não é necessariamente uma ausência de solução, mas sim um estado negativo existente. 


\begin{tabular}{|l|c|c|c|}
\hline \multicolumn{4}{|c|}{ Identificação de problemas socioambientais } \\
\hline Globais & Nacionais & Estaduais & Locais \\
\hline
\end{tabular}

Quadro 01: Matriz 1

Fonte: RIBEIRO (2016).

Para a Matriz 2 (Quadro 02), propõe-se formular as potencialidades ambientais e/ou educativas em nível global, nacional, estadual e local, como uma situação virtual positiva que existe, que se deseja manter, ou que se pretende construir.

\begin{tabular}{|l|c|c|c|}
\hline \multicolumn{4}{|c|}{ Potencialidades ambientais e/ou educativas } \\
\hline Globais & Nacionais & Estaduais & Locais \\
\hline
\end{tabular}

Quadro 02: Matriz 2

Fonte: RIBEIRO (2016).

Na Matriz 3 (Quadro 03), são identificados os problemas relacionados à realidade local, levantadas as possíveis soluções a esses problemas e elaboradas as questões sobre os problemas apontados e as possíveis respostas a elas.

\begin{tabular}{|c|c|c|c|}
\hline \multicolumn{4}{|c|}{ Seleção de problema/ possíveis soluções e questões/ possíveis respostas } \\
\hline $\begin{array}{c}\text { Problemas locais } \\
\text { identificados }\end{array}$ & Possíveis soluções & $\begin{array}{c}\text { Questões sobre os } \\
\text { problemas }\end{array}$ & Possíveis respostas \\
\hline
\end{tabular}

Quadro 03: Matriz 3
Fonte: RIBEIRO (2016).

Na Matriz 4 (Quadro 04), estabelece-se uma relação entre os problemas, as potencialidades locais e os componentes curriculares do processo formativo do qual participam os professores em formação inicial, identificando, dentro desses componentes, os instrumentos conceituais e metodológicos que podem auxiliar no entendimento e na estruturação de resposta aos problemas colocados.

\begin{tabular}{|c|c|c|c|}
\hline \multicolumn{4}{|c|}{ Matriz do currículo } \\
\hline $\begin{array}{c}\text { Problemas locais } \\
\text { identificados }\end{array}$ & $\begin{array}{c}\text { Relações com as } \\
\text { disciplinas do currículo } \\
\text { do processo formativo }\end{array}$ & $\begin{array}{c}\text { Identificação dos } \\
\text { instrumentos conceituais }\end{array}$ & $\begin{array}{c}\text { Possíveis metodologias } \\
\text { para tratamento do } \\
\text { assunto }\end{array}$ \\
\hline
\end{tabular}

Quadro 04: Matriz 4
Fonte: RIBEIRO (2016).

No trabalho desenvolvido por Ribeiro (2016), o grupo de participantes era composto por 20 professores em formação inicial, que ora trabalhavam em pequenos grupos, ora em um 
grande grupo formado por todos. Sugere-se que os pequenos grupos sejam formados por 4 ou 5 pessoas.

Os participantes, organizados em pequenos grupos, realizaram um planejamento para a construção da Matriz 1. A eles, foi solicitado que, antes da estruturação da matriz, lessem e analisassem artigos que subsidiariam a sua construção. Diferentes textos foram analisados e socializados pelos pequenos grupos.

Uma boa forma de trabalho com os textos é a utilização da técnica de ensino painel integrado, ou também chamada de grupos rotativos ou integração horizontal-vertical, definida por Veiga e Fernandes (2017, p. 76) como "uma técnica de ensino socializado, no qual os estudantes se reúnem em subgrupos com o objetivo de estudar, investigar um ou mais temas, diagnosticar sob a orientação/coordenação do professor". Nessa técnica, os estudantes trabalham em grupo, o que oportuniza compartilhar dúvidas, ideias, divergências, sínteses. Essa técnica é composta por três momentos: o momento de ação horizontal, o momento da ação vertical e o momento integrativo. Por fim, faz-se o processo de avaliação.

Após o trabalho dos pequenos grupos, as matrizes foram socializadas e analisadas pelo grande grupo, formado por todos os participantes. Foram feitos refinamentos, adequações, e coletivamente foi elaborada a Matriz 1, que serviria de base para a continuidade das ações.

Na construção da Matriz 1, tem-se como importante identificar os problemas em todos os níveis e tentar interconectá-los até mesmo para identificar a influência de nossas ações e o que pode influenciá-las em uma dimensão mais ampla, auxiliando na construção de uma cidadania planetária. É compreensível que os participantes tenham facilidade em identificar e se sensibilizar com problemas de seu entorno, não sendo isso um fator negativo, pois já não se pode falar em cidadania planetária sem uma efetiva cidadania nas esferas local e nacional.

Dos problemas listados pelos participantes, foram eleitos aqueles relacionados a implicações do uso de agrotóxicos na saúde humana e na contaminação ambiental, por comporem uma síntese de todos os problemas apresentados. Uma boa proposta é organizar esses problemas em categorias, tais como os relacionados a políticas públicas, os que envolvem questões éticas ou aspectos relacionados a sustentabilidade, ciência e tecnologia. A seleção de questões, apesar de se configurar como uma limitação para a compreensão da realidade, leva os estudantes a compreenderem a incapacidade de responder a todas as perguntas que a realidade nos coloca (ZABALA, 2002). A escolha das questões também representa um momento de acordos coletivos sobre o que se pretende saber.

A Matriz 2 foi elaborada pelo grande grupo, que, por já estar mais entrosado, conseguia organizar os momentos de falas e intervenção. Para uma melhor estruturação das 
potencialidades, é interessante a interlocução com atores diversos, o que pode ser realizado por meio de Roda de Conversa, entendida por Dalben (2017) como uma técnica de ensino e aprendizagem que permite a fala e a escuta, e a expressão por todos os participantes de suas ideias, opiniões e concepções sobre um tema proposto, em uma dinâmica de interações. Essa estratégia didática favorece a leitura crítica da realidade, uma vez que carrega a diversidade e a inclusão de ideias, estilos e pontos de vista, permitindo a habilidade de reflexão crítica, análise e síntese dos sujeitos, o que revela sua importância didática e a solução de problemas.

A elaboração da terceira matriz foi realizada com a contribuição de todos os participantes. Um deles foi escolhido como redator e, conforme as dúvidas iam surgindo e sendo discutidas, elaborava-se a questão e esta era escrita na matriz. A última coluna da matriz, que corresponde às possíveis respostas às perguntas formuladas pelo grupo, exige uma troca de ideias bastante dinâmica, bem como pesquisas para que as respostas não sejam superficiais ou cheia de achismos.

Das questões listadas na Matriz 3, o grupo escolheu quatro para estudo, acreditando que essas questões envolviam importantes conhecimentos e ressaltavam os fatores relacionados ao que havia de interesse. Essas quatro questões orientaram a construção da Matriz 4, a qual se deu por todo o grupo trabalhando coletivamente. Para o preenchimento da terceira coluna da Matriz 4, os participantes consultaram os professores dos componentes curriculares citados na segunda coluna, favorecendo o diálogo com outros atores. Para isso, tiveram alguns dias e se mobilizaram de forma negociada entre eles.

\section{REFLEXÕES ACERCA DO DIÁLOGO}

Entre as aspirações implicadas na MP, destacam-se neste texto as fundadas no diálogo. Admite-se com Paulo Freire (FREIRE, 2014) que o diálogo tem como características a cooperação, o respeito às ideias e à diversidade de experiências e saberes. No diálogo, respeitase a historicidade dos envolvidos, pois:

\footnotetext{
A experiência histórica nutre a relação dialógica e dialética, fonte de intersubjetividade e de convivência que deve existir no cotidiano escolar. Dialógica porque os sujeitos falam e escutam em paridade, igualdade, por interesses comuns, e dialética, não pela sobreposição de teses, mas como espaço aberto para o debate reflexivo, de investigação conjunta e colaborativa, como práxis social para o debate reflexivo, de investigação conjunta e colaborativa, como práxis social que visa ao desenvolvimento afetivo, cognitivo, intelectual e humano. (SÍEVES; BALLUZ, 2016, p. 47).
} 
Na defesa da importância do diálogo e na intenção de evidenciá-lo como elemento de aproximação entre QSC e MP, destacam-se três fatores favorecidos pelo diálogo e que são objetivos do trabalho com QSC: a transposição da consciência ingênua para a consciência crítica, a concretização da interdisciplinaridade e a promoção da aprendizagem de conhecimentos científicos.

A conscientização implica ultrapassar a esfera espontânea de apreensão da realidade e chegar a uma esfera crítica de tal forma que, "quanto mais conscientização, mais se 'des-vela' a realidade" (FREIRE, 1980, p. 26). A mudança do que o pensador chama de consciência ingênua, em que há uma busca de compromisso, para a consciência crítica, na qual já há um compromisso, dá-se com um processo educativo de conscientização (FREIRE, 2014), que ocorre de forma coletiva.

É por meio de uma gama de relações intersubjetivas que implicam trocas, contradições, recuos e avanços que se dá a constituição da consciência (ZITKOSKI, 2010, p. 40), e para isso é preciso "um trabalho/atividade planejada, intencional, capaz de desenvolver coletivamente novos níveis de consciência". Assim sendo, afirma-se que "a conscientização é um processo intrinsecamente intersubjetivo, que implica o diálogo e a produção de sentidos partilhados coletivamente" (ZITOSKI, 2010, p. 41).

No trabalho de construção das matrizes, há um movimento de desvelamento da realidade, um movimento de busca de entendimento dos fenômenos que é mais bem desenvolvido a partir do fazer junto, do compartilhamento. As diversas experiências e conhecimentos pessoais, somados às diferentes estratégias cognitivas utilizadas e às habilidades de pesquisa, interpretação e organização das ideias, levam a um número maior de problemas identificados, de questões propostas e de possíveis soluções/respostas.

Com relação ao fator da concretização da interdisciplinaridade, aponto que Conrado (2013) destaca a importância de conteúdos interdisciplinares para a tomada de decisão socioambientalmente responsável e acrescento que o próprio fato de se trabalhar a realidade social, que por essência é complexa, faz com que sejam mobilizados conhecimentos interdisciplinares. Porém, atenção deve ser dada para o fato de que o desejo de aprender em comunhão, como sugerem Santos et al. (2010), juntamente com a intencionalidade de partilhar saberes a partir de interesses comuns, faz emergir a interdisciplinaridade tão desejada nos processos educativos. A interdisciplinaridade, então, não é condição previamente determinada, vai se constituindo no desvelamento da realidade. Dessa forma, acredita-se que a análise de 
QSC e o uso de MP - e, nesse caso, das matrizes - trazem possibilidades para que essa intencionalidade germine e se desenvolva.

$\mathrm{Na}$ construção das matrizes, tinha-se como objeto de estudo uma realidade que deveria ser compreendida e assim encontrar meios para intervir nela com o intuito de transformá-la. Sobre essa realidade, levantaram-se questões, contudo tanto a realidade quanto as questões e as respostas para essas questões são complexas, apresentam diversas dimensões. Essa primeira aproximação, como foi realizada na construção das matrizes 1 e 2, como diz Zabala (2002), é uma aproximação metadisciplinar. Porém, o processo concreto de conhecer ou intervir na realidade é determinado pelo uso apropriado e conhecimento de alguns meios. Dada a característica do objeto de conhecimento, os instrumentos explicativos precisam passar do caráter multidisciplinar para um modelo interdisciplinar e, quiçá, transdisciplinar.

Ao reconhecer essas limitações e a potencialidade dos modelos teóricos de cada disciplina no favorecimento do entendimento do fenômeno, abrem-se possibilidades de interações. Na construção realizada pelos participantes, permitiu-se somente a participação das ciências naturais, mas era imprescindível a utilização dos modelos teóricos de outros campos de conhecimento.

Em se tratando da promoção da aprendizagem de conhecimentos científicos, entendendo que estes auxiliam na interpretação da realidade, parte-se do entendimento de que aprender é complexificar o pensamento, que aprender é um processo reconstrutivo, o que implica envolverse em outros tipos de discursos, como o discurso científico, e assim atribuir novos sentidos às palavras já compreendidas pelo discurso cotidiano. Apropriar-se do discurso da ciência se dá principalmente pelo envolvimento em conversas sobre ciências (MORAES; RAMOS; GALIAZZI, 2007). Ainda considerando que o aprender se dá em processos reconstrutivos, temse que estes ocorrem quando sujeitos interagem socialmente. Entende-se que "novos significados são elaborados pela confrontação dos entendimentos dos participantes de um grupo atuando em conjunto. Nesse processo, os envolvidos desafiam os conhecimentos uns dos outros, mediando mutuamente sua reconstrução" (MORAES; RAMOS; GALIAZZI, 2007, p. 193).

Essa cooperação, coparticipação dos sujeitos no ato de pensar sobre o objeto de conhecimento se dá na comunicação, no uso intenso da linguagem e, sendo linguagem e pensamento dialogicamente relacionados, conforme se vai complexificando a comunicação, consegue-se formular conhecimentos cada vez mais complexos sobre o tema em estudo. 
Moraes, Ramos e Galiazzi (2004) defendem que o interagir com o outro é considerado um modo constante de aprendizagem e ainda que, no coletivo, é possível desenvolver ações que isoladamente estariam além da capacidade dos sujeitos individualizados. No diálogo, ora se fala, ora se escuta; e, ao falar, o aluno também se escuta e assim vai construindo seu pensamento.

Como afirma Freire (2015, p. 57), negando a absolutização do saber e da ignorância, "ninguém sabe tudo, assim como ninguém ignora tudo". Acredita-se que os sujeitos, no diálogo proporcionado pelo uso de técnicas de MP, possam ter aumentada sua percepção ou consciência do saber pouco; e, diante dessa percepção, se preparam para saber mais; e, nesse movimento, os saberes são feitos e refeitos.

O que se apresenta aqui foi bem perceptível no caminhar do preenchimento das matrizes de forma dialogal. Alguns dos participantes possuíam vivências e conhecimentos importantes e singulares que, ao serem compartilhadas, originaram mais questionamentos e os levaram a se envolver mais com o modo de pensar das ciências, a fim de adquirir ferramentas culturais importantes.

Caminhando para a conclusão, reforço a ideia já apresentada de que são necessárias desconstruções. Apesar da importância do diálogo e de considerá-lo um atributo natural do ser humano, observa-se uma incapacidade para o diálogo, ou uma falta de disponibilidade de se abrir com o outro, ou a falta de espaço e tempo pedagógicos para se aprender e se desenvolver essa ação, e mais ainda de promoção de um diálogo profícuo que conduza a um lugar comum, em que seja possível e imprescindível o caminhar juntos.

Compreender não só o papel do aluno, mas também o do professor, no processo educacional envolvendo QSC e MP também é importante para o estabelecimento do diálogo, visto que "o aprisionamento do professor como detentor da ciência funda a dificuldade para o estabelecimento do diálogo vivido" (SÍEVES; BALLUZ, 2016, p. 48). Freire (2015, p. 67) coloca que, "na medida em que ele [o professor] dialoga com os educandos, deve chamar a atenção destes para um outro ponto menos claro, mais ingênuo, problematizando-o". Com certeza, “o papel do educador não é o de 'encher' o educando de 'conhecimento"” (FREIRE, 2015, p. 67), mas é “o de proporcionar, através da relação dialógica educador-educando educando-educador, a organização de um pensamento correto em ambos" (FREIRE, 2015, p. 67-68).

Também não se pode deixar de sinalizar a preocupação com a deficiência de espaço e tempo para o exercício de construção e reconstrução das matrizes. Em geral, o envolver-se em QSC e MP exige tempo tanto no planejamento quanto na execução. Exigem-se tempo e espaço 
também para o aprofundamento teórico e para ressignificação dos conhecimentos por conta dos estudantes. Além desses, tempo e espaço, são destacados por Noguera (2005) como limitações e dificuldades da MP a capacidade do professor, os recursos materiais e o tamanho do grupo.

\section{CONSIDERAÇÕES FINAIS}

Apresentaram-se neste texto considerações acerca da utilização de uma metodologia matricial tida como metodologia participativa para analisar questões sociocientíficas As reflexões são construídas a partir do relato de uma ação formativa que foi desenvolvida com professores em formação inicial em Ciências da Natureza e Matemática.

Compreendendo o estabelecimento do diálogo como a essência do trabalho de QSC e MP, empenha-se neste trabalho em caracterizá-lo como importante para a transposição da consciência ingênua para a consciência crítica, a concretização da interdisciplinaridade e a promoção da aprendizagem de conhecimentos científicos. Entendido dessa forma, defende-se o uso da metodologia matricial em análise de QSC, não desconsiderando os desafios e as dificuldades existentes.

Com essa análise, ratifica-se a ideia de que é possível contribuir mais efetivamente para a formação dos sujeitos ao se usar metodologias que privilegiem a participação, o compartilhamento, a colaboração e a cooperação na abordagem de QSC.

\section{REFERÊNCIAS}

ARAÚJO, José Carlos de Souza. Da metodologia ativa à metodologia participativa. In: VEIGA, Ilma Passos Alencastro (org.). Metodologia participativa e as técnicas ensinoaprendizagem. Curitiba: CRV, 2017. p. 17-56.

CARVALHO, Julyana Cardoso; DANTAS, Josivânia Marisa. Revisão no campo: a utilização de questões sociocientíficas para a formação docente entre 2007 e 2017. Indagatio Didactica, v. 11, n. 2, ago. 2019, p. 449-462. Disponível em:

https://proa.ua.pt/index.php/id/article/view/6202. Acesso em: 18 abr. 2020. DOI: https://doi.org/10.34624/id.v11i2.6202.

CARVALHO, Lizete Maria Orquiza de; CARVALHO, Washington Luiz Pacheco de (orgs.). Formação de professores e questões sociocientíficas no ensino de ciências. São Paulo: Escrituras Editora, 2012.

CONRADO, Dália Melissa. Uso de conhecimentos evolutivo e ético na tomada de decisão por estudantes de biologia. 2013. 220f. Tese (Doutorado em Ecologia) - Instituto de Biologia, Universidade Federal da Bahia, Salvador, 2013. Disponível em: 
https://repositorio.ufba.br/ri/bitstream/ri/24732/1/Tese-DaliaMelissaConrado-2017-QSCCTSA-Final.pdf. Acesso em: 18 abr. 2020.

COSTA, Helder Martins. A educação em ciências e a intervenção sociopolítica em questões socioambientais e sociocientíficas: uma experiência na formação inicial de professores e educadores Da Investigação às Práticas, v. 7, n. 2, p. 71-90, 2016. Disponível em: http://www.scielo.mec.pt/scielo.php?script=sci_abstract\&pid=S218213722017000200006\&lng=pt\&nrm=iso. Acesso em: 19 abr. 2020.

DALBEN, Ângela Imaculada Loureiro de Freitas. Roda de Conversa: uma estratégia didática na sala de aula e na formação continuada de educadores em escala. In: VEIGA, Ilma Passos Alencastro (org.). Metodologia participativa e as técnicas de ensino-aprendizagem. Curitiba: CRV, 2017. p. 137-168.

FREIRE, Paulo. Pedagogia do oprimido. 56. ed. ver. e atual. Rio de Janeiro: Paz e Terra, 2014.

FREIRE, Paulo. Extensão ou comunicação? 17. ed. São Paulo: Paz e Terra, 2015.

MARTÍNEZ PÉREZ, Leonardo Fabio. A abordagem de questões sociocientíficas na formação continuada de professores de ciências: contribuições e dificuldades. 2010. 351f. Tese (Doutorado em Educação para a Ciência) - Universidade Estadual Paulista, Faculdade de Ciências, Bauru, 2010. Disponível em: http://hdl.handle.net/11449/102011. Acesso em: 18 abr. 2020.

MARTÍNEZ PÉREZ, Leonardo Fabio. Questões sociocientíficas na prática docente: ideologia, autonomia e formação de professores. São Paulo: Editora da UNESP, 2012. Disponível em: http://aia-cts.web.ua.pt/wp-content/uploads/2015/08/1Questoes_sociocientificas_na_pratica_docente-Web_2.pdf. Acesso em: 18 abr 2020.

MEDINA, Naná Mininni; SANTOS, Elizabeth da Conceição. Educação ambiental: uma metodologia participativa de formação. Petrópolis, RJ: Vozes, 1999.

MORAES, Roque; RAMOS, Maurivan Guntzel; GALIAZZI, Maria do Carmo. A epistemologia do aprender no educar pela pesquisa em ciências: alguns pressupostos teóricos. In: MORAES, Roque; MANCUSO, Ronaldo (orgs.). Educação em ciências: produção de currículos e formação de professores. Ijuí: Ed. Unijuí, 2004. p. 85-108.

MORAES, Roque; RAMOS, Maurivan Guntzel; GALIAZZI, Maria do Carmo. Aprender Química: promovendo excursões em discurso da Química. In: ZANON, Lenir Basso; MALDANER, Otavio Aloisio (orgs.). Fundamentos e propostas de ensino de Química para educação básica no Brasil. Ijuí: Ed. Unijui, 2007. p. 191-210.

NOGUERA, Fernando López. Metodología participativa em la enseñanza universitária. 3. ed. Madrid: Narcea, S. A. de Ediciones, 2005.

NUNES-NETO, Nei; CONRADO, Dália Melissa. Introdução. In: CONRADO, Dália Melissa; NUNES-NETO, Nei (orgs.). Questões sociocientíficas: fundamentos, propostas de ensino e perspectivas de ação. Salvador: EDUFBA, 2018. p. 15-23. 
RAMALHO, Betânia Leite; NUÑEZ, Isauro Beltran. Aprendizagem da docência, formação e desenvolvimento profissional: trilogia da profissionalização docente. In: RAMALHO, B. L.; NUÑEZ, I. B. (orgs.). Formação, representações e saberes docente. Elementos para se pensar a profissionalização dos professores. Campinas, SP: Mercado das Letras; Natal, RN: UFRN, 2014. p. 17-37.

RATCLIFFE, Mary; GRACE, Marcus. Science Education for citizenship: teaching socioscientific issues. USA: Open University, 2003.

REIS, Pedro. Da discussão à ação sociopolítica sobre controvérsias sócio-científicas: uma questão de cidadania. Ensino de Ciências e Tecnologia em Revista, v. 3, n. 1, p. 1-10, jan./jun. 2013. Disponível em:

https://repositorio.ul.pt/bitstream/10451/9577/3/DA\%20DISCUSS\%C3\%830\%20\%C3\%80\% 20A\%C3\%87\%C3\%830.pdf. Acesso em: 18 abr. 2020.

RIBEIRO, Katia Dias Ferreira. Formação de professores de ciências naturais em uma perspectiva interdisciplinar e crítica: reflexões sobre a contribuição da vivência com questões sociocientíficas na mobilização e aprendizagem de conhecimentos para a docência. 2016. 357f. Tese (Doutorado em Educação em Ciências e Matemática) - Universidade Federal de Mato Grosso, Rede Amazônica de Educação em Ciências e Matemática, Programa de Pós-Graduação em Ensino de Ciências e Matemática, Cuiabá, 2016.

RIBEIRO, Katia Dias Ferreira; DARSIE, Marta Maria Pontin. As questões sociocientíficas no enfrentamento aos desafios da interdisciplinaridade na formação de docentes de ciências naturais e matemática. In: LATIN AMERICAN SCIENCE EDUCATION RESEARCH ASSOCIATION, 2018, Guayaquil. Anais... Guayaquil, 2018. CR-ROM.

RIBEIRO, Katia Dias Ferreira; DARSIE, Marta Maria Pontin. Espaços curriculares para discussão de questões sociocientíficas na formação de docentes em Ciências Naturais. Latin American Journal of Science Education, v. 1, p. 13006-1 - 13006-12, 2014.

RIBEIRO, Katia Dias Ferreira; DARSIE, Marta Maria Pontin. Mobilização/construção de conhecimentos para a docência na formação docente mediada pela vivência de análise de uma questão sociocientífica. In: LATIN AMERICAN SCIENCE EDUCATION RESEARCH ASSOCIATION, 2016, San Jose. Anais... San Jose, 2016a. CR-ROM..

RIBEIRO, Katia Dias Ferreira; DARSIE, Marta Maria Pontin. O contexto da Amazônia Legal na formação de professores de Ciências Naturais: a constituição de elementos para a estruturação de uma ação formativa. In: LATIN AMERICAN SCIENCE EDUCATION RESEARCH ASSOCIATION, 2016, San Jose. Anais... San Jose, 2016b. CR-ROM.

RIBEIRO, Kátia Dias Ferreira; TREVISAN, Andreia Cristina Rodrigues; TREVISAN, Eberson Paulo. Tratamento de uma situação problema com uso de uma metodologia matricial como favorecedora da aprendizagem de conhecimentos para a docência. In: ENCONTRO INTER-REGIONAL NORTE, NORDESTE E CENTRO-OESTE SOBRE FORMAÇÃO DOCENTE PARA A EDUCAÇÃO BÁSICA E SUPERIOR (ENFORSUP) E II ENCONTRO INTERNACIONAL SOBRE FORMAÇÃO DOCENTE PARA A EDUCAÇÃO BÁSICA E SUPERIOR (INTERFOR), 2017. Anais... Palmas: UFT, 2017. 
SANTOS, Wildson Luiz Pereira dos; MORTIMER, E. F. Abordagem de aspectos sociocientíficos em aulas de ciências: possibilidade e limitações. Investigações em Ensino de Ciências, v. 14, n. 2, p. 191-218, 2009. Disponível em:

https://www.if.ufrgs.br/cref/ojs/index.php/ienci/article/view/355/222. Acesso em: 18 abr. 2020 .

SANTOS, Wildson Luiz Pereira dos; SILVA; Karolina Marins Almeida e; SILVA, Shirley Margareth Buffon da. Perspectivas e desafios de estudo de QSC na educação científica brasileira. In: CONRADO, Dália Melissa; NUNES-NETO, Nei (orgs.). Questões sociocientíficas: fundamentos, propostas de ensino e perspectivas de ação. Salvador: EDUFBA, 2018. p. 427-451.

SANTOS, Wilson Luiz Pereira dos et al. O Enfoque CTS e a Educação Ambiental: possibilidades de "ambientalização" da sala de aula de Ciências. In: SANTOS, W. L. P. dos; MALDANER, O. A. (orgs.). Ensino de Química em foco. Ijuí: Ed. Unijuí, 2010. p. 131-157.

SAUCEDO, Kellys Regina Rodio; PIETROCOLA, Maurício. Características de pesquisas nacionais e internacionais sobre temas controversos na Educação Científica. Ciênc. Educ., Bauru, v. 25, n. 1, p. 215-233, 2019. Disponível em:

http://www.scielo.br/scielo.php?script=sci_arttext\&pid=S1516-73132019000100215. Acesso em: 18 abr. 2020.

SAVIANI, Dermeval. Pedagogia histórico-crítica: primeiras aproximações. 11. ed. ver. Campinas, SP: Autores Associados, 2013.

SÍEVES, Luiz; BALLUZ, Elsa Helena Almeida Silva. Diálogos: desafios e possibilidades para (re)pensar a prática docente. In: SIVERES, L. (org.). Diálogo: um princípio pedagógico. Brasília: Liber Livro, 2016. p. 43-55.

SOUSA, Polliane Santos de; GHELEN, Simoni Tormöhlen. Questões sociocientíficas no ensino de ciências: algumas características das pesquisas brasileiras. Revista Ensaio, v. 19, p. 1-22, 2017. Disponível em: http://www.scielo.br/pdf/epec/v19/1983-2117-epec-19-e2569.pdf. Acesso em: 18 abr. 2020.

VEIGA, Ilma Passos Alencastro; FERNANDES, Rosana César de Arruda. Painel integrado ou grupos rotativos: caminhos para a integração horinzotal-vertical. In: VEIGA, Ilma Passos Alencastro (org.). Metodologia participativa e as técnicas ensino-aprendizagem. Curitiba: CRV, 2017. p. 75-85.

ZABALA, Antoni. Enfoque globalizador e pensamento complexo: uma proposta para o currículo escolar. Tradução Ernani Rosa. Porto Alegre: Artmed, 2002.

ZITKOSKI, Jaime José. Paulo Freire \& a Educação. 2. ed. Belo Horizonte: Autêntica Editora, 2010.

Submetido em: 19 de abril de 2020 .

Aprovado em: 21 de junho de 2020. 